\title{
Sobre la portada
}

\footnotetext{
L
} a imagen que ilustra la portada de este número corresponde a la fachada de la casa que alberga al Instituto Mora, ubicada a un costado de la plaza del antiguo barrio de San Juan, en Mixcoac, al sur del Distrito Federal. Esta antigua barriada se sobrepuso a la expansión urbana y mantuvo el sabor provinciano que le daban el grito de los vendedores ambulantes, el repique de las campanas que marcaban las horas del rezo y de las misas, el paso del tranvía y la vida sencilla y monótona de sus habitantes. El crecimiento incontrolable de la urbanización llegó a esta comunidad: se vendieron los ranchos y se fraccionaron las haciendas, se derribaron las viejas casas unifamiliares para dar paso a los grandes edificios de departamentos, aparecieron los autobuses y automóviles. El barrio quedó delimitado por cuatro grandes avenidas: Patriotismo, al oriente; Extremadura, al sur; Holbein, al norte, e Insurgentes, al poniente. Sus calles adquirieron los nombres de pintores y escultores. Actualmente ya no pasa el tranvía ni los vendedores ambulantes; los automóviles se han apoderado de las calles y de las banquetas. Pero aun así, el lugar continúa luchando por su conservación: se mantienen sus fiestas, la plaza, la verdulería, la sastrería, la carpintería y la miscelánea. La plazuela aún sirve de solaz a los vecinos y a los que sin ser sus moradores se acomodan en las bancas para retomar fuerzas y tener un instante de descanso. En su espacio se han situado puestos de jugos, de flores y de comidas donde reinan los pambazos, las gorditas y las quesadillas. Todavía, en pleno siglo XXI, esta plaza se engalana, se viste de fiesta, se estremece con los cohetes que anuncian las celebraciones de San Juan y de la Virgen de Guadalupe. Su fuente y sus árboles colocados en espacios simétricos de formas triangulares y rectangulares, protegidos por cercas de hierros, dan sosiego y sombra a los que por ella pasan. En uno de ellos, en el más cercano a una de sus esquinas, se encuentra el busto de don Valentín Gómèz Farías, firmado por "Miramontes" y realizado en "Guadalajara" en 1974.

El sitio está enmarcado por la iglesia y dos edificios: uno es la sede principal del Instituto Mora; el otro, el monasterio de Santa Catalina de Siena, donde monjas de la orden dominica se recogen en clausura. En el claustro se puede comprar galletas, rompope, tamales y chiles en nogada. Anteriormente el hoy convento fue la casa del periodista y poeta Ireneo $\mathrm{Paz}$, abuelo del escritor Octavio 
Paz. La plaza y sus edificios develan hoy el paso del tiempo: conservan huellas de su pasado y se mantienen vivos en el presente.

La reproducción en comento es el detalle de la fotografía que fue tomada por Carlos Hernández y Felipe Morales, técnicos del Departamento Audiovisual de Investigación Social del Instituto Mora. La imagen completa (que se muestra en la página 7) es un plano general de la fachada, con un ángulo normal; la cámara se encuentra a nivel. La toma fue hecha con una moderna cámara digital, con una resolución de 300 dpi y en formato de $8 \times 10$. Por la sombra que proyectan los árboles podemos determinar que fue tomada hacia el mediodía. En esta imagen podemos apreciar que la fachada se compone de dos cuerpos. En el primero destaca la puerta de entrada que tiene dos hojas de madera de las que sólo se abre la parte baja correspondiente a la medida humana; la enmarcan dos pilares y a ambos lados dos faroles; sobre el pilar del lado derecho aparece el número 12 y en seguida se observa una gran ventana cuyo vano se encuentra cerrado por una celosía de madera, entre esta y la puerta se localiza un pequeño recuadro. En el segundo -en la parte superior de la construcción- se destacan dos arcos rebajados con un barandal corrido de hierro tras el cual se ven seis grandes macetones; está coronado por un nicho enmarcado por dos pequeñas pilastras. Sobre la cornisa se pueden apreciar dos gárgolas. Complementan la fotografía dos ventanas con balcón cerrado con herrería. Destacan en este retrato dos pendones: uno presenta la imagen del doctor José María Luis Mora y está colgado al lado izquierdo de la puerta justo sobre un bloque de cantera que lleva el nombre del Instituto Mora. El segundo muestra la figura de Emiliano Zapata, que da cuenta de la publicación del número conmemorativo de los 100 años de la revolución mexicana en la revista BiCentenario. Si bien en la imagen no salen los árboles se advierte su presencia por el gran follaje que cubre casi toda la parte superior de la toma; su sombra cubre parte de la plaza y de la calle.

Durante muchos años fue propiedad de la familia Gómez Farías, y aquí es donde vivió don Valentín. Más adelante fue adquirida por las compañías Azufrera Panamericana y Explotadora del Istmo, quienes la donaron, en 1976, para que albergara el proyecto de Bibliotecas Mexicanas, A. C. Posteriormente, en 1981, se convirtió en la sede principal del Instituto José María Luis Mora.

De entonces a la fecha la construcción se ha transformado. En su interior se han adaptado oficinas, una moderna sala de cómputo, una librería y un aula, conocida con el nombre de "sala Mozart" por la escultura de este músico que se sitúa en una de sus esquinas. En el jardín se ha situado una cafetería y en la parte de lo que fuera la huerta se ha construido un moderno, edificio donde se ubican el acervo de la biblioteca que reúne más de 93000 títulos en 163135 volúmenes especializados en historia y ciencias sociales; aulas donde se imparten clases y seminarios de las maestrías en Historia Moderna y Contemporánea de México, Estudios Regionales, Sociología Política y Cooperación Internacional, así como el doctorado en Historia Moderna y Contemporánea. Todos estos 


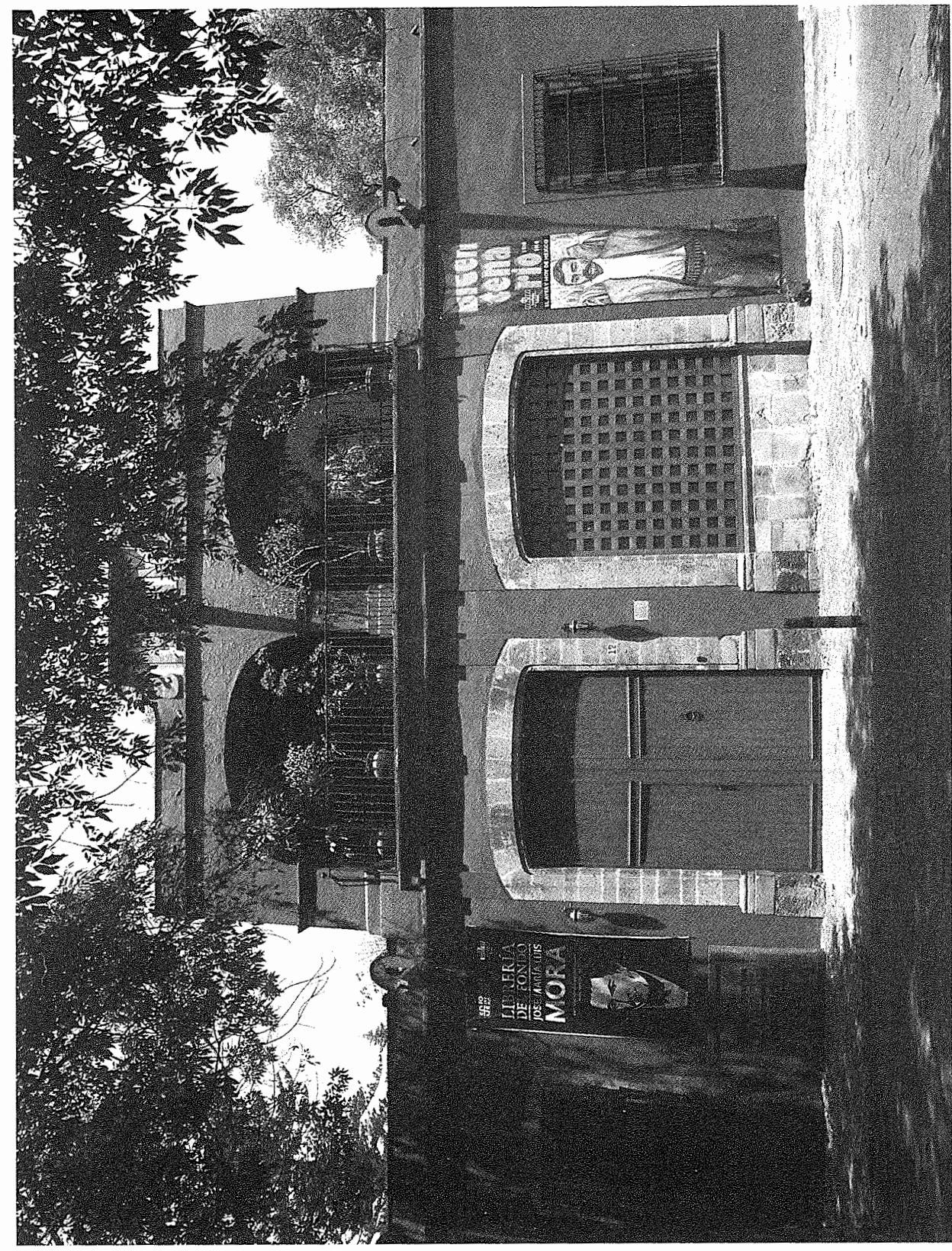


programas docentes se encuentran registrados en el Padrón Nacional de Posgrados de Calidad del CONACYT. Recientemente, se estableció la licenciatura en Historia. Por su parte, las maestrías en Estudios Regionales, en Cooperación Internacional y el programa del doctorado en Historia Moderna y Contemporánea mantienen la categoría de competencia internacional. En este edificio también se hallan cubículos para los profesores-investigadores. Posteriormente, en las últimas décadas del siglo Xx, el Instituto Mora abrió dos nuevas sedes: una en Coyoacán, que alberga aulas, el Laboratorio Audiovisual de Investigación Social, la Subdirección de Publicaciones y cubículos para profesores-investigadores; la otra en la colonia Del Valle en la que se encuentran el área administrativa y el departamento de Restauración y Conservación de Libros.

En 1992 el Instituto Mora quedó integrado al sistema SEP-CONACYT y en la actualidad se distingue como uno de los centros públicos de investigación dependientes del CONACYT. En el área de investigación se fueron definiendo nuevas líneas y temas que permiten aportar nuevos conocimientos, nuevas herramientas y nuevas metodologías. Se cuenta con un importante archivo de la palabra y un laboratorio audiovisual de investigación social. De sus 58 investigadores, 48 se encuentran en el Sistema Nacional de Investigadores; 53 son doctores y cinco tienen el grado de maestros. Todos ellos discuten, forman alumnos, dirigen tesis, participan en conferencias, coloquios y seminarios, forman redes, participan en proyectos interinstitucionales, publican libros, capítulos y artículos en diferentes revistas tanto nacionales como internacionales. En el aspecto editorial las publicaciones del Mora son ampliamente reconocidas; las revistas Secuencia y América Latina en la Historia Económica se encuentran indexadas en el padrón de CONACYT. Por su parte, la revista BiCentenario se va consolidando como una importante revista de divulgación.

El trabajo y las aportaciones que -en el campo de la historia y las ciencias sociales- han hecho sus profesores-investigadores, la calidad de sus publicaciones, la riqueza de su acervo bibliográfico, la excelencia de sus programas docentes y la eficiencia del personal de apoyo han llevado a la consolidación del Instituto Mora como una institución de excelencia académica.

\section{Regina Hernández Franyuti INSTITUTO MORA}

